\title{
Groupwork on the edge Embracing the messiness of group facilitation with marginalised peoples
}

\author{
Neil Richard Hall ${ }^{1}$
}

\begin{abstract}
This article reports on a poster presentation at SWSD18 which explored concepts of discomfort and messiness in terms of what they mean for participants, facilitators and auspicing agencies of groupwork. Where 'tidy' theory does not prepare social workers for the 'messiness' of groupwork practice, the poster proposes a model for working with group processes that captures both linear and organic understandings. Further, the poster explores opportunities for maximising the benefits of groupwork in the context of unpredictable group processes as well as participants' and facilitators' potentially chaotic lives.
\end{abstract}

Keywords: theory in practice; group stages; discomfort; group work benefits

1. Director of Academic Program (Social Work \& Community Welfare), Western Sydney University, Australia

Address for correspondence: n.hall@westernsydney.edu.au

Date of first (online) publication: 20th January 2021 
Groupwork is a key intervention method in social work. I have been engaged in facilitating groups with people for three decades in many settings including adolescent health, alcohol and other drugs, juvenile justice, prisons, homelessness services, Indigenous groups and community-based agencies, particularly in marginalised areas of Western Sydney (Australia). I have also been lecturing in groupwork in undergraduate and post-graduate social work programs for 20 years. My parallel teaching and practice in groupwork provide a unique reflexivity to find re-imagined and effective ways forward in this space. Although there is a very useful range of readings relating to groupwork with marginalised people, I have found that many of them leave important areas up to individual interpretation. On one hand, this absence of prescription does allow for some flexibility in practice, but more often than not it can leave groupworkers floundering when it comes to situations where the 'tidy' theory does not match the very real situation of working with 'harder' \& 'messier' marginalised groups. Apart from the challenge of balancing the multiple roles of a group facilitator, this mismatch puts workers in situations where they may lose confidence. Furthermore, workers also stand at risk of straying into unethical practice and potentially doing more harm than good; through poorly conceived, inadequately planned and unprofessionally delivered groupwork interventions. The ideas proposed through this poster are based on my continual critical reflection of the interplay between groupwork theory and practical experience of group facilitation. My hope is that we will find ways to apply the theoretical basis and fundamental skills of groups to working with marginalised people and to facilitating groups in those unpredictable, flexible and informal settings in which social workers invariably find themselves. Embracing the mess starts with rethinking some current understandings of groups which tend to conceive of group process as either being linear, cyclical or organic.

A linear model sees the helping process running though groups as clinical, organised, and sequential. Egan (2014) and Cournoyer (2016), for example, have a linear model of the helping process that begins or ends up in a linear way. We of course know Tuckman's (1965) model of group stages and we all remember them because they rhyme: forming, storming, norming, performing, and mourning. He suggests that groups always follow those stages, perhaps for different amounts of time but always follow and always in this order. Cyclical models are still 
somewhat sequential but tend to be a little more fluid or responsive to the situation. For example, Slattery (1994) suggests that each individual session starts with engaging with people, inviting and exploring responses, promoting difference and then closing. The cycle continues as the group members re-engage in the following week. Prochaska et al (1992) 'Stages of Change' model is familiar, where they propose that to be able to change people start at a point generally where they know they need to, maybe they move through a step of realising that they do need some kind of change in their life, then making preliminary decisions, then taking action, maintaining that change and then perhaps moving into a relapse. There are multiple exit points but the change in the learning gets more substantial each time you go around. An organic position understands groups as far less rigid and far more responsive to immediate need. McDermott (2002), Crago (2006) and Yalom \& Leszez (2005), for example, reflect on groups as being dynamic, random or in the moment - having almost a life of their own.

What I've suggested in this poster is that you can blend these linear, cyclical and organic understandings of group flow into this 'Model of Group Evolution'. I think the model more closely portrays the range of groupwork experiences we might encounter in our social work practice settings.

While there is a general forward direction that groups move from start to end (overlaid on Tuckman's five stages), there is also some movement back and forth between the various phases together with circular movement within them through different points and times. For example, a group may get to the point of having negotiated their goals and negotiated their behaviours (that is, what they're going to do and how they're going to be with each other) but a new member might join a group and they have to go back and renegotiate those things. So the group members re-engage, reform an intention and differentiate their roles again if needed. Similarly, when a group is in what Tuckman calls 'performing', the combination of group members' skills, knowledge and resources enables collaborative relationships to strengthen as they work towards achieving an agreed goal. However, sometimes different tasks will mean working in more concentrated relationships with different people, and so those processes may circulate as collaborations change.

This model also accepts the fact that there's work to do before a group commences, which is labelled 'conception', that incorporates concept 
development, planning, recruitment and any pre-group assessment of potential group members. In this regard, it is vital to consider that this activity is actually part of the whole group process. Equally, there is more work to do after a group ends and is labelled 'infusion'. The processing of closing a group requires the consideration of how group members will take their learning, development and relationships forward into their lives beyond the immediate group experience. This aspect of the model also allows the cycle to continue through reflection and evaluation (short, medium and long term) to inform how group members are, how we can do the group better next time, or perhaps how we can work with the same cohort of people but in a more effective way if necessary.

This model for groups in social work can be further understood through thinking about a rollercoaster as an analogy. Rollercoasters provide an extreme experience which some people love and some people hate. A rollercoaster looks random and is a very 'in-the-moment' experience but there is in fact a great deal of safety, through regulations, overseen by a supervisor and they do still follows the rails. Groups have the same kind of edge to them: some people love them; some people hate them. They can feel random and extreme but there is safety and guidance by a facilitator. A group is in the moment but still follows some kind of sense of boundary and direction. In all this, though, the passage of group evolution still has its members' goals, needs and relationships at its' core.

There are some other factors that influence the direction that groups take through this model, and can include the type of group (such as therapeutic, educational, self-help or social action oriented, or combinations of multiple types; Benjamin et al 1986) and the length of the group, including whether it is open-ended and has openmembership. The context in which the group operates can also have an impact, such as how membership was determined, geographic location and agency support. Once a group is in the habit of meeting, the different communication patterns that are occurring and the kind of learning styles people are connecting with also effect its' progress. Furthermore, the facilitator's experience has a part to play in how well the group moves around and through this model of evolution. What we do know is that we're delving into people's lives and people - human beings - are complex. 
There are times when people come to us for help through groupwork and they're generally coming as people who are struggling, hurting, traumatised, vulnerable, and yet also bringing agendas - a complicated mix of things to be dealing with. Even with a blend of multiple understandings captured by the model, groupwork is still messy and sometimes that can cause discomfort both for group members and facilitators. Acknowledging that the greater amount of discomfort is always going to be felt by group participants, the poster indicates some of the areas in which facilitators may feel discomfort and provides some suggested strategies for responding. For example, if we're uncomfortable about the unknown, then the correct response is to engage - we need to take time to engage with the people, we need to take time to engage with the process, and we need to take time to engage with the content. Similarly, if the unexpected is what causes discomfort, then planning is a really, really useful strategy. Now that may seem a little bit contradictory because you can not plan for every contingency, but you can plan for a lot of them, and the planning becomes easier and more comprehensive with experience. It may seem counter-intuitive but the better planned you are, the abler you will be to respond to situations in the moment. Planning also helps for being able to justify our decisions and actions in facilitating group, through being connected with a theoretical framework and a grounding in why we're doing what we're doing. Having a very clear purpose for everything you do in a group is vital so that we do not just use some kind of activity as a way of filling in time or because people might think it's a fun thing to do. In social work we need to be much more clear, planned and purposeful than that.

There are always going to be times where the messiness of groupwork is more difficult to come to grips with but there are some ways to minimise this discomfort. As group facilitators, we need to admit that it's always going to be messy and it's fairly certain that group participants are going to be far more intensely uncomfortable than us. So, that any risks that we take to go beyond our own comfort zone are minimal in comparison to the discomforts and the risks that our group participants are going to be taking. We shouldn't expect everything to be tied into a nice package because messiness is a normal part of human groupwork experience. 


\section{Note}

You can watch a video presentation related to the poster via either of these 2 URLs below or by scanning the QR code on the poster itself:

https://www.reverbnation.com/neilhall/videos

https://www.youtube.com/watch?v=mvUf8cxFln $8 \& \mathrm{t}=1 \mathrm{~s}$

\section{References}

Benjamin J., Bessant J., and Watts R., (1997) Making Groups Work: Rethinking practice, St. Leonards, NSW, Allen \& Unwin

Cournoyer, B. (2016) The Social Work Skills Handbook. Boston: Cengage Learning

Crago H. (2006) Couple, Family and Group Work: First steps in interpersonal intervention. Maidenhead, UK: Open University Press

Egan G, 2014, The Skilled Helper: A problem-management and opportunitydevelopment approach to helping. (10th ed.) Belmont, CA: Brooks/Cole, Cengage Learning

McDermott, F. (2002) Inside Group Work. Crows Nest, NSW, Allen \& Unwin Prochaska, J.O., DiClemente, C.C., and Norcross, J.C. (1992) In search of how people change: applications to the addictive behaviors. American Psychologist, 47, 1102-1114

Slattery P. (1994) Questions of Choice. Sydney: NSW Department of Education. Tuckman B.E. (1965) Development sequence in small groups. Psychological Bulletin, 63, 384-399

Yalom I.D. and Leszez, M. (2005) The Theory and Practice of Group Psychotherapy. ( $5^{\text {th }}$ ed.) New York: Basic Books 